\title{
Accelerated Weathering Performances of Furfurylated and Acetylated Bamboo Sheets
}

\author{
Krisdianto, Peter Vinden, and Simon Prezwloka
}

\begin{abstract}
Bamboo material is a potential wood substitute given that its physical and mechanical properties are comparable with those of wood. As lignocellulose material, bamboo is also degraded for use outdoor. Two significant chemical modification for wood which may work for bamboo material are acetylation and furfurylation. This paper evaluates the weathering performance of furfurylated and acetylated bamboo sheets. Parameters studied include colour changes and contact angle after accelerated weathering process at QUV chamber. The result shows that the total colour differences $\left(\Delta E^{*}\right)$ of furfurylation is higher than non-modified strips, while colour differences of acetylated bamboo strips are less than nonmodified strips. To summarize, chemically modified sheets turn grey after weathering. Slowing of lignin photo-degradation by acetylation is attributed to the acetyl groups, which limits the degradation of lignin. Treating bamboo sheets with acetic anhydride and furfuryl alcohol was found to be effective in protecting bamboo from absorbing water during weather exposure.
\end{abstract}

Keywords: Bamboo sheets, acetylation, furfurylation, accelerated weathering, colour, contact angle.

\section{Introduction}

Bamboo is a woody, valuable and robust material. It grows naturally on all continents except Europe (Liese 1987) and shows potential as a wood substitute given that its physical and mechanical properties are comparable with those of wood. The most significant advantage of bamboo is its growth rate, where bamboo grows up to 30 meters within six months in some tropical countries, demonstrating the potential of substituting bamboo for slower-growing wood species to increase annual yield (Liese 1987). Additionally, the extensive root network makes bamboo a stable carbon fixate, erosion controller and water table preserver. Bamboo is an essential means of establishing reforestation and often has a positive effect on groundwater levels and soil improvement via the nutrients in its debris (van der Lugt et al. 2009).

Bamboo species are of enormous importance to rural people in several regions of Asia. For many centuries bamboo has played an essential role in the daily life of the people of tropical countries (Sharma 1980; Jifan 1985). Traditionally it is used for light building materials, scaffolding, ladders, mats, baskets, containers, tool handles, pipes, fencing, handicrafts, toys and musical instruments. In addition to traditional applications, modern processing techniques have considerably extended its usefulness in applications such as ply bamboo, bamboo mat board and laminated bamboo for flooring (Recht and Wetterwald 1992; Nugroho and Ando 2001).

Anatomically, the culm wall structure consists of vascular bundles which are embedded in ground parenchyma tissues. Vascular bundles are not uniformly distributed inside culms. Numerous smaller bundles are present towards the outer portions, while larger but fewer bundles are found towards the central region of the culms
(Kumar and Dobriyal 1992). The outer part, which is protected by hard kitin bark is more resistant to outdoor exposure than the inner part of the bamboo, is less resistant than those of the outer part. Exposing material to outdoor conditions is not only placing material in direct contact with solar radiation but also to rapid changes of moisture (Feist 1983). Solar radiation that contains ultraviolet light initiates photochemical degradation, which is identified through colour changes in the material (Chang et al. 1982). Water sorption during outdoor exposure causes uneven shrinkage and swelling that initiates material degradation. Outdoor exposure to inner part bamboo has not been studied intensively.

Currently, environmental concerns regarding the use of chemicals for wood preservation has generated interest in alternatives method such as chemical modification (Hill 2006). Wood modification is a means of altering the material to overcome one or more of its disadvantages. Two major chemical modification processes for wood modification are acetylation and furfurylation (Jones 2007). Acetylation replaces hydroxyl groups in wood lignin with acetyl groups, and as a result, the material is more dimensionally stable, and the natural durability is improved (Rowell et al. 1993; 1994). Furfurylation is based upon the reaction of wood with the bio-chemical furfuryl alcohol at the cell wall level. Both processes significantly improve wood properties, protecting against decay, decreased hygroscopicity and improved dimensional stability (Jones and Hill 2007). Acetylation and furfurylation have not been implemented for bamboo material. Sugiyanto (2011) reported that both methods are potential for enhancing bamboo sheets properties.

Weathering performance is defined as the extent of degradation after the material is exposed to outdoor conditions. In an outdoor climate, the material is in direct contact with solar radiation, moisture, heat, atmospheric 
pollutants and microorganisms and components are thus degrade with exposure (Pospisil and Nespurek 2000; Xie et al. 2005). Lignocellulosic materials such as wood and bamboo are responsive to outdoor environmental factors (Feist 1983). The use of bamboo in outdoor conditions has not been extensively studied (Liese 1987). Similar to wood, photo-degradation and moisture changes during exposure are the predominant factors driving bamboo degradation. During exposure, uneven shrinkage and swelling lead to the surface checking of bamboo (Feist 1983; Kim et al. 2008). $\mathrm{Kim}$ et al. (2008) reported that exposing bamboo culm to outdoor conditions for less than 12 months transformed its colour to grey with numerous checks occurring. Anatomically, most parenchyma tissues are degraded. Lignin rapidly decreases during the initial weathering period (Kim et al. 2008). The effect of weathering upon chemically modified bamboo has not been studied intensively.

Two essential parameters of weathering performance include colour changes and moisture sorption. Colour differences due to weathering can be measured quantitatively using a colourimetry based system characterized by three parameters: $L^{*}, a^{*}$ and $b^{*}$ for easy quantification. The $L^{*}$ value represents the lightness, while $a^{*}$ and $b^{*}$ are the redness and yellowness values. The total colour changes $\left(\Delta E^{*}\right)$ due to weathering is precisely measured before and after weathering (Zhang et al. 2009). Moisture sorption in the wood after exposure can be determined based upon its surface wettability (Kalnins and Feist 1993). Surface wettability can be determined based upon the contact angle between the liquid and wood surfaces. Two techniques available for contact angle measurement include sessile drops and tilting plate methods. The sessile drop method involves placing a drop of water on the wood surface and measuring the contact angle at a specific time (Wellons 1980; Kalnins and Feist 1993). The tilting plate method involves immersion of the flat wood surfaces in distilled water followed by tilting until the wood-water interface is no longer curved (Freeman 1959; Bodig 1962). A sessile drop is a simple way to measure contact angle and accordingly has been widely used to measure the contact angle of exposed wood (Kalnins and Feist 1993). This paper evaluates the weathering performance of furfurylated and acetylated bamboo sheets. Parameters studied include colour changes and contact angle after accelerated weathering process at QUV chamber.

\section{Materials and Methods}

\section{Sample Preparation}

Bamboo strips were prepared from three years old petung bamboo (Dendrocalamus asper (Schultes f.) Backer ex Heyne). To fit the QUV/Spray V-230 A8 chamber, bamboo sheets $(75 \times 4 \times 3 \mathrm{~mm})$ were cut from bamboo culm (Fig. 1). Bamboo samples were matched from the same internodes and grouped into three sets (acetylated, furfurylated and non-modified). Bamboo was acetylated and furfurylated based upon the treatment methods, as mentioned by Sugiyanto (2011). Only the optimum level of chemical modification was tested: $16 \%$ weight percentage gain for acetylated samples and $76 \%$ for furfurylated samples. After modification, all samples together with nonmodified bamboo were placed in a conditioning room $\left(25^{\circ} \mathrm{C}\right.$, $65 \%$ relative humidity) until the equilibrium moisture content was reached within three weeks.
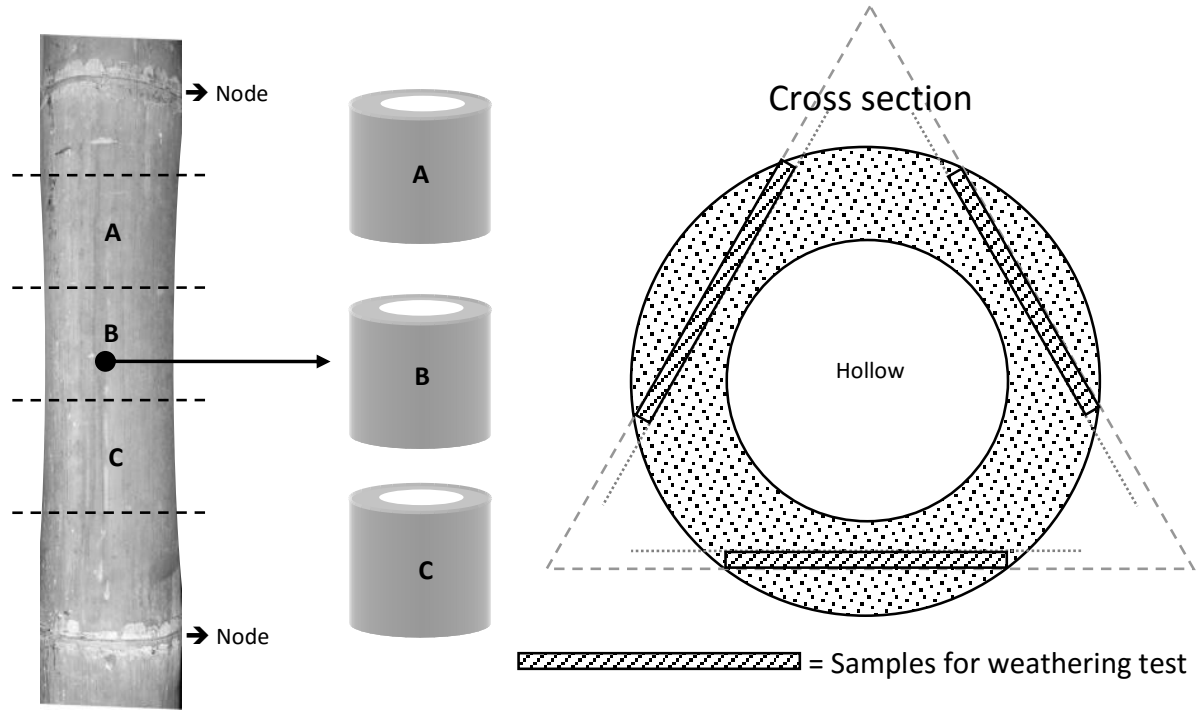

Figure 1. Sample pattern for weathering test. 


\section{Accelerated Weathering Test}

The main weathering forces that cause material degradation include sunlight, high temperature and moisture exposure (Q-Lab 2006). Outdoor weathering tests are timeconsuming, and such forces vary considerably producing significantly variable results. Consequently, various chambers designed to mimic accelerated weathering conditions have been developed to test material behaviour in outdoor use (Q-Lab 2006).

The QUV/Spray V-230 A8 accelerated weathering chamber has been developed for testing materials under specific outdoor conditions (Q-Lab 2006). The QUV/Spray $\mathrm{V}$-230 A8 chamber can reproduce the damage that may occur over months or even years of outdoor exposure in hours. The apparatus is equipped with UVA-340 lamps to simulate shortwave sunlight within the chamber. The chamber also simulates exposure to moisture as the dew, with cycles of heating and condensation. The apparatus is equipped with water sprays to mimic the effects of rain as well as thermal shock and erosion (Q-Lab 2006). Section 12 examines the impact of weathering upon acetylated and furfurylated bamboo sheets using the QUV/Spray V-230 A8 accelerated weathering chamber. Colour change and contact angle differences (by the sessile drop method) are investigated. The QUV/Spray V-230 A8 weathering chamber was used for weathering accelerated testing. Samples were subjected to accelerated weathering by exposure to $340 \mathrm{~nm}$ fluorescent UV lamps (Fig. 2). The weathering schedule involved continuous light irradiation (2 hours) followed by water spraying (18 minutes) (ASTM International 2010). The average irradiance was $0.85 \mathrm{~W} / \mathrm{m}^{2}$ at $340 \mathrm{~nm}$ wavelength with a chamber temperature of $45^{\circ} \mathrm{C}$. The output of a 340 $\mathrm{nm}$ lamp is concentrated in the UV region ranging from 300 $400 \mathrm{~nm}$ with an apex at $340 \mathrm{~nm}$. Ninety-six bamboo sheets, mounted on the sample holder (Fig. 2) were monitored every 300 hours for a total of 1200 hours. Each inspection consisted of colour and contact angle measurements.
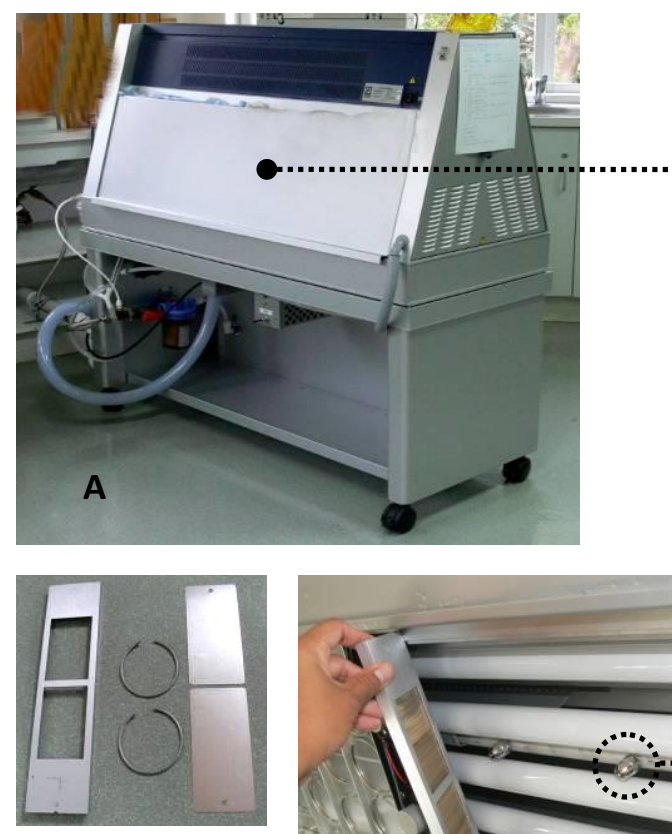

C

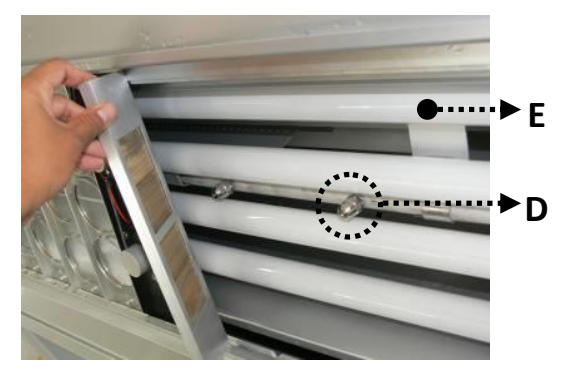

Key:
A. QUV/Spray V-230 A8 weathering chamber
B. Mounted samples
C. Aluminium sample holder
D. Water spraying nozzle
E. $340 \mathrm{~nm}$ ultraviolet lamp

Figure 2. The QUV/Spray V-230 A8 weathering chamber and samples mounted on the aluminium sample holder of the chamber slots.

\section{Colour Measurement}

Colour values before and after weathering were measured using a Minolta CR-300 tristimulus colour measuring instrument. The colour value was presented using the Commission International de l' Eclairage (CIE) $1976\left(L^{*}, a^{*}, b^{*}\right)$ colour space, also known as the CIELAB system. There are three coordinates: $L^{*}$ represents lightness $\left(100=\right.$ white, $0=$ black), $a^{*}$ value represents redness $\left(+a^{*}=\right.$ red, $-a^{*}=$ green $)$ and $b^{*}$ represents yellowness $\left(+b^{*}=\right.$ yellow, $-b^{*}=$ blue). Total colour changes $\left(\Delta E^{*}\right)$ value were calculated based on $L^{*}, a^{*}$ and $b^{*}$ value differences (Equation 1 and 2). A low $\Delta E^{*}$ corresponds to a low colour change or a stable colour. 


$$
\begin{aligned}
& \Delta L^{*}=L_{f}^{*}-L_{i}^{*} ; \Delta a^{*}=a^{*}{ }_{f}-a^{*}{ }_{i} \\
& \Delta b^{*}=b^{*}-b^{*}{ }_{i} \ldots \ldots \\
& \Delta E^{*}=\sqrt{\Delta L^{*}+\Delta a^{*}+\Delta b^{* 2}}
\end{aligned}
$$

Where $\Delta L^{*}, \Delta a^{*}$ and $\Delta b^{*}$ are the changes between the initial $(i)$ and the final $(f)$ values. $\Delta E^{*}$ is the total colour changes.

\section{Contact Angle Measurement}

Contact angles before and after weathering exposure were measured using the sessile drop technique. Twentyfive-micron litre $(\mu \mathrm{l})$ of distilled water was dropped onto the bamboo surface and recorded using a Dyno $3111 \mathrm{~S}$ digital video camera (Fig. 3). Measurement of contact angles was made on still video images, and quantification of the angle was recorded based upon the digital images using 'Image-J' software (Rasband 2003). For consistency, contact angle comparisons were made 10 seconds after dropping time.

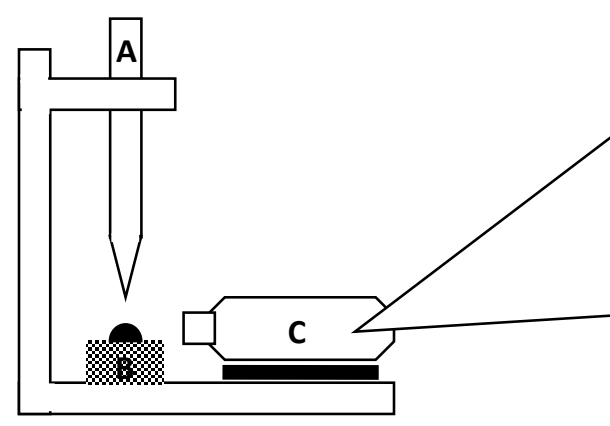

Key:
A. Micro pipette
B. Bamboo sheet
C. Digital video camera Dyno $3111 \mathrm{~S}$
D. Contact angle measurement after 10 seconds
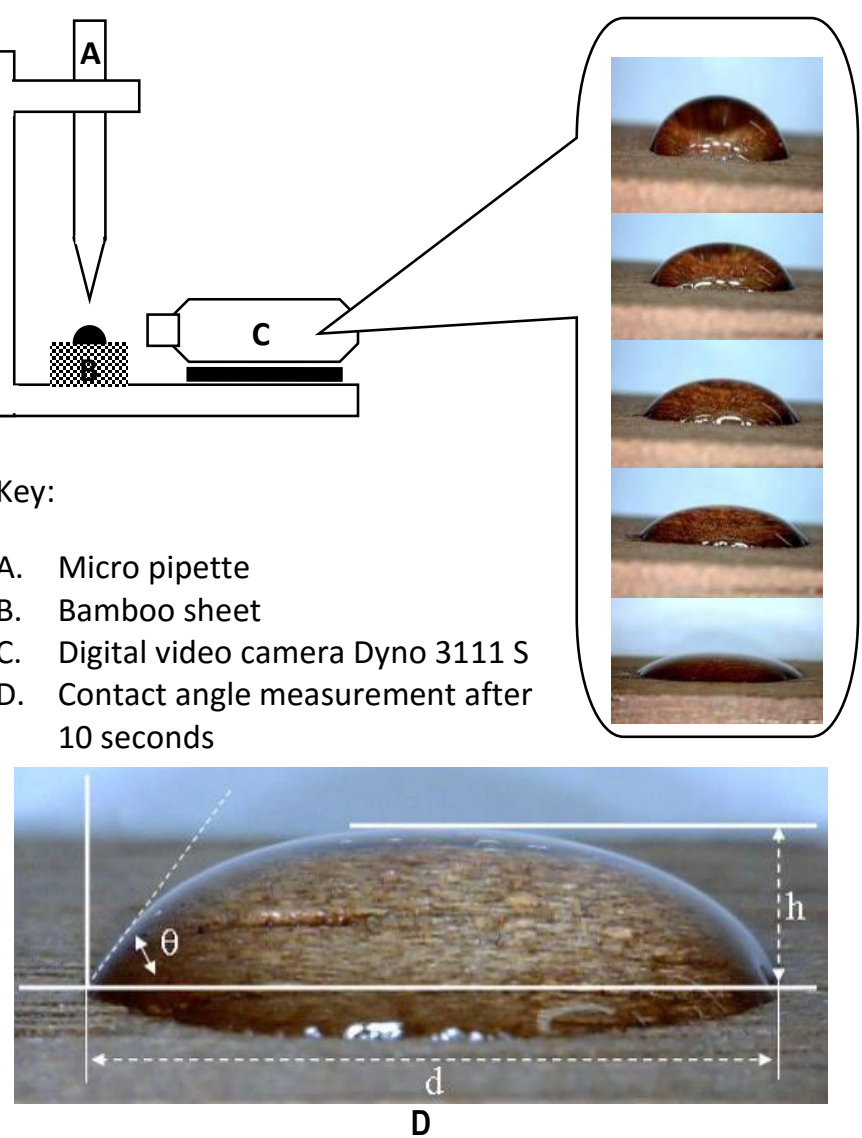

Figure 3. Contact angle measurement using the sessile drop technique.

\section{Results and Discussion}

\section{Colour Differences}

The average colour value differences of chemically modified and non-modified bamboo sheets after weathering are presented in Table 1.

Table 1 shows that after weathering, the greatest $\Delta E^{*}$ was recorded in furfurylated sheets, while $\Delta E^{*}$ of acetylated sheets achieved the lowest value. Less colour value differences $\left(\Delta E^{*}\right)$ indicates less change of colour due to weathering. That is, less $\Delta E^{*}$ means colour stability of bamboo sheets after exposure. The colour value differences between bamboo sheets increased with longer exposure time. The greatest lightness differences $\Delta L^{*}$ was recorded in furfurylated bamboo sheets, while the $\Delta L^{*}$ of acetylated and non-modified sheets were similar. The increase of $\Delta L^{*}$ (lightness value) indicates most sheets tend to be whitish after exposure. The redness $\left(a^{*}\right)$ and yellowness $\left(b^{*}\right)$ values of weathered sheets were negative, meaning the sheets turned greenish and bluish after 
exposure. In combination between $L^{*}, a^{*}$ and $b^{*}$ values, the sheets turn to grey after weathering.

The normality of data set (Shapiro-Wilk) (Table 2) shows that the colour value differences before and after weathering of bamboo strips conformed with a normal distribution except the weathering of non-modified strips for 600 hours. Therefore, a one-way ANOVA was applied in the case of normally distributed data, while Kruskal-Wallis oneway ANOVA with ranks were examined for non-Gaussian data (Field 2005).
The results of a two-way ANOVA performed on groups of chemically modified strips (acetylation, furfurylation and non-modified) and weathering time (300,600, 900 and 1200 hours) into the total colour differences $\left(\Delta E^{*}\right)$ demonstrated significant differences between treatments $(F=41.116, p<$ 0.001 ), while there were no significant differences among weathering exposure time $(F=2.661, p=0.053)$. The total colour differences $\left(\Delta E^{*}\right)$ of bamboo strips after weathering is shown in Fig. 4.

Table 1. The average colour value differences after weathering.

\begin{tabular}{|c|c|c|c|c|c|c|c|c|}
\hline \multirow[t]{3}{*}{ Sample groups } & \multicolumn{8}{|c|}{ Weathering exposure time (hours) } \\
\hline & \multicolumn{2}{|c|}{300} & \multicolumn{2}{|c|}{600} & \multicolumn{2}{|c|}{900} & \multicolumn{2}{|c|}{1200} \\
\hline & $x$ & $s d$ & $x$ & $s d$ & $x$ & $s d$ & $x$ & $s d$ \\
\hline & \multicolumn{8}{|c|}{$\Delta L^{*}$ (unit) } \\
\hline Non-modified & 3.9 & 0.6 & 2.4 & 0.7 & 3.2 & 1.3 & 2.8 & 1.5 \\
\hline Acetylated & 3.8 & 0.8 & 2.3 & 1.3 & 3.1 & 0.9 & 3.2 & 1.1 \\
\hline \multirow[t]{2}{*}{ Furfurylated } & 5.4 & 0.3 & 5.6 & 0.5 & 5.8 & 1.1 & 5.7 & 0.4 \\
\hline & \multicolumn{8}{|c|}{$\Delta a^{*}$ (unit) } \\
\hline Non-modified & -1.2 & 0.1 & -1.3 & 0.1 & -1.5 & 0.2 & -1.5 & 0.1 \\
\hline Acetylated & -0.7 & 0.1 & -0.9 & 0.5 & -1.3 & 0.5 & -1.4 & 0.3 \\
\hline \multirow[t]{2}{*}{ Furfurylated } & -0.8 & 0.1 & -0.6 & 0.3 & -0.7 & 0.2 & -0.8 & 0.4 \\
\hline & \multicolumn{8}{|c|}{$\Delta b^{*}$ (unit) } \\
\hline Non-modified & -3.4 & 0.3 & -4.3 & 1.3 & -3.9 & 1.3 & -4.2 & 1.2 \\
\hline Acetylated & -1.6 & 0.2 & -3.7 & 1.1 & -3.3 & 1.0 & -2.5 & 1.4 \\
\hline \multirow[t]{2}{*}{ Furfurylated } & -1.4 & 0.2 & -2.2 & 0.6 & -2.1 & 0.8 & -2.2 & 0.7 \\
\hline & \multicolumn{8}{|c|}{$\Delta L^{*}$ (unit) } \\
\hline Non-modified & 5.3 & 0.5 & 5.3 & 0.9 & 5.5 & 0.3 & 5.6 & 0.3 \\
\hline Acetylated & 4.2 & 0.7 & 4.6 & 1.1 & 4.8 & 1.0 & 4.6 & 0.4 \\
\hline Furfurylated & 5.6 & 0.3 & 6.1 & 0.3 & 6.3 & 0.9 & 6.3 & 0.3 \\
\hline
\end{tabular}

Remarks: $x=$ mean; $s d=$ standard deviation

Table 2. Results of Shapiro-Wilk test for colour changes $\left(\Delta E^{\star}\right)$ of bamboo strips after weathering.

\begin{tabular}{ccccc}
\hline Colour differences & \multicolumn{4}{c}{ Accelerated weathering test (hours) } \\
\cline { 2 - 5 } & 300 & 600 & 900 & 1200 \\
\hline Non-modified & & & $0.990^{*}$ & $0.950^{*}$ \\
$\Delta L$ & $0.890^{*}$ & 0.766 & $0.833^{*}$ & $0.979^{*}$ \\
$\Delta a$ & $0.944^{*}$ & 0.788 & $0.919^{*}$ & $0.879^{*}$ \\
$\Delta b$ & $0.936^{*}$ & 0.773 & $0.990^{*}$ & $0.950^{*}$ \\
$\Delta E$ & $0.890^{*}$ & 0.766 & & \\
\hline Acetylated & & & $0.899^{*}$ & 0.782 \\
$\Delta L$ & 0.782 & $0.945^{*}$ & $0.945^{*}$ & $0.884^{*}$ \\
$\Delta a$ & $0.908^{*}$ & $0.832^{*}$ & $0.969^{*}$ & $0.979^{*}$ \\
$\Delta b$ & $0.934^{*}$ & $0.950^{*}$ & $0.899^{*}$ & 0.782 \\
\hline$E$ & $0.782^{*}$ & $0.945^{*}$ & & $0.911^{*}$ \\
\hline Furfurylated & & & $0.878^{*}$ & $0.872^{*}$ \\
$\Delta L$ & $0.968^{*}$ & $0.955^{*}$ & $0.926^{*}$ & $0.882^{*}$ \\
$\Delta a$ & $0.917^{*}$ & $0.875^{*}$ & $0.957^{*}$ & $0.911^{*}$ \\
\hline$\Delta b$ & $0.943^{*}$ & $0.989^{*}$ & $0.878^{*}$ &
\end{tabular}

Remarks: * indicates data matches with the pattern of normal distribution 


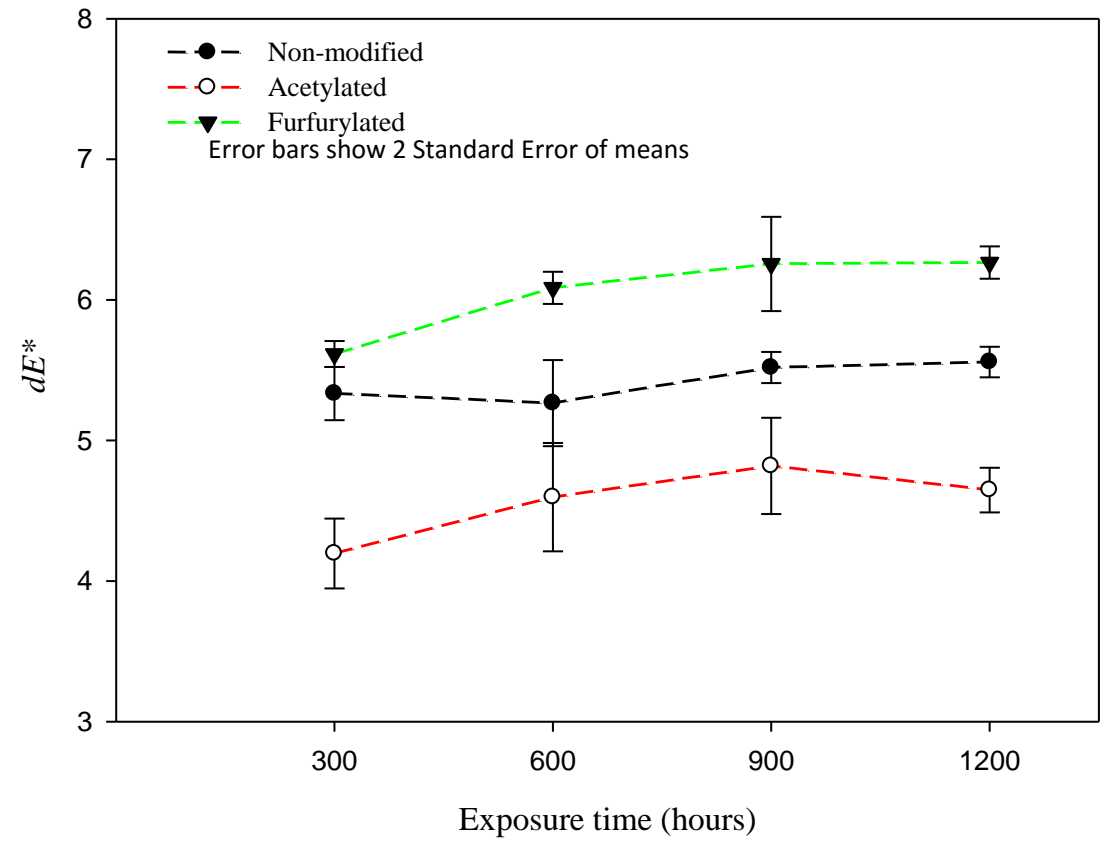

Figure 4. Average values of total colour differences $\left(\Delta E^{*}\right)$ of bamboo strips after accelerated weathering.

Fig. 4 shows that the total colour differences $\left(\Delta E^{*}\right)$ of furfurylation are greater than non-modified strips, while colour differences of acetylated bamboo strips is less than non-modified strips. The difference in the mean values of treated bamboo strips is greater than would be expected by chance; as a result, there is the statistical difference $(p=<$ 0.001 ). The difference in mean values of exposure time is not significant enough to exclude the possibility that the difference is just due to random sampling variability. The graph in Fig. 4 also shows the colour difference tends to increase with longer exposure time.

Similar to wood, bamboo naturally contains several chromophoric functional groups and an aromatic skeleton, making it a good absorber of light. During exposure to solar radiation, which includes ultraviolet light, various reactions are initiated with lignocellulosic components (primary and secondary hydroxyl, carbonyl, carboxyl, aromatic and phenolic groups) (Evans et al. 2005; Xie et al. 2005). Photochemical degradation is evident by changes in colour to yellow or brown, which proceed to an eventual greying (Chang et al. 1982; Feist 1983).

In all bamboo sheets examined, colour differences $\Delta E^{*}$ values are higher than 1.5 , which means colour differences can be visually distinguished by the human eye (Horváth and Halász-Fekete 2005). After weathering, bamboo strip colour tended to become greyish. Similarly, with that of weathered wood, the greyish colour after exposure confirmed the photo-degradation of lignin, extractives and bonded chemical (Zhang et al. 2009). Slowing down of lignin photo-degradation by acetylation is attributed to the acetyl groups which limit the lignin degradation.

\section{Contact Angle (Wettability)} Table 3.

The average contact angle values are shown in Table 3. Average contact angle values.

\begin{tabular}{lrrr}
\hline Bamboo sheets & $\begin{array}{c}\text { Exposure } \\
\text { (hours) }\end{array}$ & \multicolumn{2}{c}{ Contact angle $\left({ }^{\circ}\right)$} \\
Non-modified & 0 & 54.0 & $s d$ \\
& 300 & 35.0 & 0.9 \\
& 600 & 31.1 & 0.8 \\
& 900 & 30.8 & 0.6 \\
& 1200 & 30.1 & 0.8 \\
\hline Furfurylated & 0 & 53.6 & 1.3 \\
& 300 & 47.3 & 0.7 \\
& 600 & 43.3 & 0.7 \\
& 900 & 42.2 & 1.6 \\
Acetylated & 1200 & 42.3 & 1.3 \\
& 0 & 53.5 & 1.3 \\
& 300 & 51.3 & 0.8 \\
& 600 & 51.7 & 1.4 \\
& 900 & 50.6 & 1.0 \\
& 1200 & 50.7 & 1.2 \\
\hline
\end{tabular}

Remarks: $x=$ mean; $s d=$ standard deviation.

Table 3 shows the average contact angle value decreased with longer exposure time. Weathered samples 
exhibited lower contact angles than the initial samples, indicating that bamboo sheets easily absorb water after weathering. The average contact angle of non-modified bamboo sheets decreased significantly from $54^{\circ}$ to $30^{\circ}$ after 1200 hours of exposure. The average contact angle of furfurylated sheets decreased slightly from $54^{\circ}$ to $42^{\circ}$ after 1200 hours of exposure. The contact angle in acetylated bamboo sheets reduced from $53^{\circ}$ to $50^{\circ}$ after 1200 hours of exposure.

The measured contact angle at 10 seconds after dropping time on the weathered sheet's surfaces, as a function of the exposure duration, is presented in Fig. 5 . Normality test (Shapiro-Wilk) of contact angles showed that the data were normally distributed; therefore, a two-way ANOVA was performed. The results of two-way ANOVA between modified strips (acetylated, furfurylated and nonmodified) and exposure time (300, 600, 900 and 1200 hours) showed that both factors (treatment and exposure time) were significantly different with $\mathrm{F}=2501.3(\mathrm{p}<0.001)$ for treatment and $F=704.41(p<0.001)$ for exposure time.

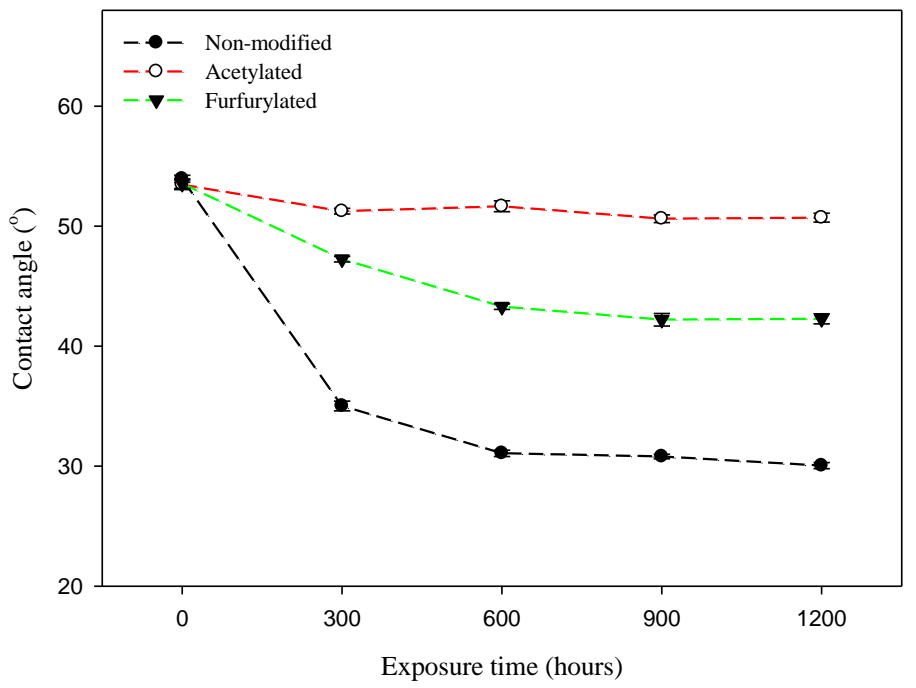

Figure 5. The contact angle of non-modified and chemically modified bamboo sheets after accelerated weathering

Fig. 5 shows the contact angle measurement of bamboo sheets after accelerated weathering. Weathered, non-modified sheets exhibited lower contact angles than chemically modified sheets. Weathering, through the action of artificial sunlight and water spray in the QUV/Spray V-230 A8 chamber, caused gradual destruction of the bamboo sheets. Most bamboo tissues were degraded, and nonmodified sheets easily absorbed water following weathering. These findings are in accord with those of Kim et al. (2008) who found most ground parenchyma was degraded during initial weathering and the bamboo surface became more wettable, and water repellency was reduced.

The initial contact angle of non-modified bamboo sheets was around $54^{\circ}$ and decreased to $35^{\circ}$ after 300 hours of exposure. After a further 300 hours of exposure, the contact angle was further reduced to $30^{\circ}$. Contact angles did not significantly change in subsequent examinations (900 and 1200 hours). In wood, Kalnins and Feist (1993) attributed decreases in contact angle to the photo-oxidation of extractives to volatile products and the removal of water-soluble compounds. The value of the contact angle of chemically modified sheets confirmed that acetyl groups and furan polymer slow down the wettability of the weathered bamboo sheets surfaces.
Lignin and extractives are known to be partially responsible for the water repellency of wood and the high hydrophilic property of cellulose (Rowell and Banks 1985). Any slight modification of lignin and extractives in the wood will contribute to the alteration of the contact angle. The reduction in the contact angle of weathered bamboo sheets is a strong indication that weathering promotes the degradation of lignin and extractives.

The contact angles of both acetylated and furfurylated bamboo sheets were also reduced but not to the same magnitude as non-modified sheets. The angles of acetylated sheets were decreased by $2-4^{\circ}$ after 300 and 600 hours of exposure but were not significantly reduced after 900 and 1200 hours of exposure. The contact angle of furfurylated bamboo sheets rapidly fell by $6^{\circ}$ in the first 300 hours but diminished after 600,900 and 1200 hours of exposure. The contact angles of chemically modified bamboo sheets were higher than non-modified bamboo sheets after weathering. That is, chemically modified bamboo sheets did not easily absorb water after weathering.

Similar to those of wood, during weathering bamboo sheets exposed to rapid moisture changes during outdoor exposure (Xie et al. 2005). Water from rain or dew on the wood surface is quickly absorbed by capillarity on the surface layer, followed by adsorption within wood cell walls. 
Water vapour is taken up directly by the wood by adsorption under increased relative humidity and causes the swelling. Uneven swelling between the surface and interior may result in surface warping, cupping and surface checking after outdoor exposure (Feist 1983).

In the case of wood, the exposure to such areas allows the initiation of degradation during outdoor exposure. To protect the wood in outdoor conditions, treatment with acetic anhydride has been used. Plackett et al. (1992) reported that acetylated wood was adequately protected from degradation due to decreased moisture sorption. Wood discolouration due to weathering cannot, however, be reduced (Plackett et al. 1992).

\section{Conclusions}

The study shows that the total colour differences $\left(\Delta E^{*}\right)$ of furfurylation are greater than non-modified strips, while colour differences of acetylated bamboo strips are less than non-modified strips. To summarize, chemically modified sheets turn grey after weathering. Slowing of lignin photo-degradation by acetylation is attributed to the acetyl groups, which limits the degradation of lignin. Treating bamboo sheets with acetic anhydride and furfuryl alcohol was found to be effective in protecting bamboo from absorbing water during weather exposure.

\section{References}

American Standard Testing and Material (ASTM) International. 2010. Standard Practice for Operating Fluorescent Light Apparatus for UV Exposure of Nonmetallic Materials. ASTM International. G154 - 06, p. 11.

Bodig, J. 1962. Wettability Related to Gluability of Five Philippine Mahoganies. Forest Products Journal 12(6): 265-270.

Chang, S.T.; D.N.S. Hon; and W.C. Feist. 1982. Photodegradation and Photoprotection of Wood Surfaces. Wood and Fiber Science 14(2): 104-117.

Evans, P.D.; M.J. Chowdhury; B. Mathews; K. Schmalzl; S. Ayer; M. Kiguchi; and Y. Kataoka. 2005. Handbook of Environmental Degradation of Materials. William Andrew, Inc.

Feist, W.C. 1983. Weathering and Protection of Wood, in M.D. Stevensville (ed.), Seventy-ninth annual meeting of American Wood-Preservers' Association, Kansas City, Vol. 79, pp. 192-205.

Field, A. 2005. Discovering Statistics Using SPSS. 2nd Edition. Sage Publications Ltd., London. p.779.

Freeman, H.G. 1959. Relationship Between Physical and Chemical Properties of Wood and Adhesion. Forest Products Journal 9(12): 451-458.

Hill, C.A.S. 2006. Wood Modification Chemical, Thermal and Other Processes, Renewable Resources. John Wiley \& Sons Ltd., West Sussex, England. p.239.
Horváth, H.Z. and M. Halász-Fekete. 2005. Instrumental colour measurement of paprika grist, in Annals of the Faculty of Engineering, Faculty of Engineering Hunedora, 101-107.

Jifan, Z. 1985. Bamboo Development in China', in A.N. Rao, G. Dhanarajan \& C.B. Sastry (eds), International Bamboo Workshop, Hangzhou, China.

Jones, D. 2007, in C.A.S. Hill, D. Jones, H. Militz \& G.A. Ormondroyd (eds), The Third European Conference on Wood Modification, Cardiff, UK, pp. 439-446.

Jones, D. and C.A.S. Hill. 2007. Wood Modification - A Brief Overview Technology, in The $5^{\text {th }}$ COST E34 International Workshop, Bled, Slovenia.

Kalnins, M.A. and W.C. Feist. 1993. Increase in Wettability of Wood with Weathering. Forest Products Journal 43(2): 55-57.

Kim, J.S.; K.H. Lee; M.Y. Cha; and Y.S. Kim. 2008. Anatomical, Physical and Chemical Changes of Bamboo (Phyllostachys pubescens) During Weathering Processes. Paper presented to International Research Group on Wood Protection, Istanbul, Turkey, 25-29 May, IRG/WP 08-10650

Kumar, S. and P.B. Dobriyal. 1992. Treatability and Flow Path Studies in Bamboo. Part I Dendrocalamus strictus Nees, Wood and Fiber Science 24(2): 113117.

Liese, W. 1987. Research on Bamboo. Wood Science and Technology 21(3): 189-209.

Nugroho, N. and N. Ando. 2001. Development of Structural Composite Products Made from Bamboo II: Fundamental Properties of Laminated Bamboo Lumber. Journal of Wood Science 47(3): 237-242.

Plackett, D.V.; E.A. Dunningham; and A.P. Singh. 1992. Weathering of Chemically Modified Wood. Accelerated Weathering of Acetylated Radiata pine. Holz als Rohund Werkstoff 50(4): 135-140.

Pospisil, J.and S. Nespurek, S. 2000. Photostabilization of Coatings. Mechanisms and Performance. Polymer Science 25(9): 1261-1335.

Q-Lab. 2006, Operating Manual of QUV Accelerated Weathering Tester', Q-Lab Headquarters \& Instruments Division.

Rasband, W.S. 2003. ImageJ. viewed 14 August 2007, $</ /$ rsb.info.nih.gov/ij/>.

Recht, C. and M.F. Wetterwald. 1992. Bamboos, Timber Press, Portland, Oregon. p.160.

Rowell, R.M.; R.S. Lichtenberg; and P. Larsson. 1993. Stability of Acetylated Wood to Environmental Changes. Wood and Fiber Science 25(4): 359-364.

Rowell, R.M. and W.B. Banks. 1985. Water Repellency and Dimensional Stability of Wood. Forest Products Laboratory, Madison.

Rowell, R.M.; R. Simonson; S. Hess; D.V. Plackett; D. Cronshaw; and E. Dunningham. 1994. Acetyl Distribution in Acetylated Whole Wood and Reactivity 
of Isolated Wood Cell-wall Components to Acetic anhydride. Wood and Fiber Science 26(1): 11-18.

Sharma, Y.M.L. 1980. Bamboo in the Asia Pacific Region, in G. Lessard \& A. Chorinard (eds), Workshop on Bamboo Research in Asia, Singapore.

Sugiyanto, K. 2011. Physical and Chemical Modification of the Bamboo Species Dendrocalamus asper. PhD Thesis. The University of Melbourne, Australia.

Van der Lugt, P.; J. Vogtlander; and H. Brezet. 2009. Bamboo, a Sustainable Solution for Western Europe Design Cases, LCAs and Land-use, 30, International Networking of Bamboo and Rattan, Beijing, China. p. 108.

Wellons, J.D. 1980. Wettability and Gluability of Douglas-fir Veneer. Forest Products Journal 30(7): 53-55.

Xie, Y.; A. Krause; C. Mai; H. Militz; K. Richter; K. Urban; P.D. Evans; and P.D. 2005. Weathering of Wood
Modified with the $\mathrm{N}$-methylol compound 1,3dimethylol-4,5-dihydroxyethyleneurea', Polymer Degradation and Stability 89(2): 189-199.

Zhang, J.; D.P. Kamdem; and A. Termiz. 2009. Weathering of Copper-amine Treated Wood. Applied Surface Science 256(3): 842-846.

Krisdianto

Forest Products Research and Development Center

Jl. Gunung Batu 5, Bogor - Indonesia 16610

E-mail : kris.sugiyanto73@gmail.com

Peter Vinden and Simon Prezwloka

School of Forestry, The University of Melbourne, Australia VIC 3365 